\title{
Regional Implications of Financial Market Development: Industry Location and Income Inequality
}

\author{
CRED Research Paper No. 1
}

Maximilian von Ehrlich

University of Bern,

Department of Economics and CRED
Tobias Seidel

University of Duisburg-Essen

October, 2013

\begin{abstract}
We develop a heterogeneous-firms model with trade in goods, labor mobility and credit constraints due to moral hazard. Mitigating financial frictions reduces the incentive of high-skilled workers to migrate to one region such that an unequal distribution of industrial activity becomes less likely. Hence, financial market development has opposite regional implications as trade liberalization. While the former leads to more dispersion of economic activity across space, the latter tends to drive clustering. This has immediate implications for income inequality both between regions and skill groups. According to our model, financial development reduces inequality in both dimensions.
\end{abstract}




\section{Introduction}

There has been a long and still unsettled debate whether the integration of markets leads to a more or less equal distribution of economic activity and thus income across regions. While the conventional view suggests that market integration should lead to convergence and thus more equal living conditions, there is also a prominent opposition claiming that market integration magnifies inequality (Myrdal, 1957, Lewis, 1977, Krugman 1991). The latter argument fuels policy makers' fears that market integration benefits primarily rich regions with a large home market. Accordingly, many federations have regional policies in place that transfer resources from the core to the peripheral regions. For instance, the European Union spends about 50 billion euros per year on regional cohesion representing about one third of the overall EU budget. ${ }^{1}$ In Germany, it is even stated in the constitution that governments have to ensure sufficiently equal living conditions across regions. There is surprisingly little work that links the role of financial markets to this debate. It is surprising because the importance of the financial sector for the real economy is widely acknowledged and we have seen a very pronounced development of financial markets in recent decades.

We show that more developed financial markets work towards more equality of income both within and across regions. This implies that deeper financial markets allow for more integrated product markets (that promise welfare gains from trade) without jeopardizing the goal of equal regional living conditions. The underlying economic mechanism for these results builds on access to external finance. Deeper financial markets allow the least productive firms to get funded which raises the number of firms, but reduces the share of exporters. This reduces inter-regional competition of firms such that clustering of economic activity turns out less attractive. As trade liberalization raises the share of exporters, a reduction in transport costs stimulates regional inequality which is well understood.

Our model features trade in goods, labor migration, credit constraints, endogenous entry and exit of heterogeneous firms, and occupational choice (for the latter see Lucas, 1978, and Egger and Kreickemeier, 2008, 2012). The financial friction stems from a moralhazard problem in the tradition of Holmstrom and Tirole (1997). While entrepreneurs

\footnotetext{
${ }^{1}$ Regional cohesion is the second largest item of the EU budget amounting to more than 350 billion euros during 2007-2013 and 336 billion euros during 2014-2020 (see EU Commission, 2011).
} 
can choose their effort level to maximize their payoff, lenders cannot directly observe the managers' behavior. Hence, asymmetric information introduces credit constraints as lenders demand a higher return from a given investment to ensure a higher payoff for entrepreneurs and thus diligent behavior. This leads to credit rationing as less productive firms cannot commit to diligence despite positive net present values. To obtain these selection effects, we need to introduce some kind of firm heterogeneity. We deviate from Holmstrom and Tirole (1997) in ignoring different endowments of firm assets, but rather follow Melitz (2003) in introducing different levels of productivity. This helps us capturing the well-documented fact that the smallest (i.e. least productive) firms benefit most from financial development (Beck, Demirgüç-Kunt, and Maksimovic, 2005, Beck, DemirgüçKunt, Laeven, and Levine, 2008).

The building blocks of our model are strongly supported by empirical evidence. There is a growing literature in international economics that has identified financial market development as an important determinant of trade flows and foreign direct investment (FDI). Lower credit constraints may generate a comparative advantage (Egger and Keuschnigg, 2010a and 2010b, Ju and Wei, 2011) and lead to more exports both in terms of volume and destinations (Beck 2002 and 2003, Manova, 2008 and 2012, Muûls, 2008). ${ }^{2}$ Further, several influential empirical papers have identified economic determinants for the location of industry. For example, Davis and Weinstein (2002) show that locational fundamentals are crucial for the pattern of economic activity across space, but increasing returns to scale determine the intensity of concentration. Ellison, Glaeser and Kerr (2010) disentangle the three Marshallian explanations for agglomeration: (i) technology spillovers, (ii) labor market pooling, and (iii) proximity to input suppliers (vertical linkages) to save transport costs. They find that the latter features most prominently in the data. Even though input-output linkages are not present in our model, it can be shown that the resulting location pattern results from the same forces as in Krugman (1991) on which we build. Moreover, Davis and Weinstein (2003), Hanson and Xiang (2004) and Redding and Sturm (2008) provide convincing evidence for the home-market effect which is at the center of the location mechanism in our model.

\footnotetext{
${ }^{2}$ Chor, Foley, and Manova (2008) show that development of financial markets in the host country reduces horizontal FDI due to more entry and thus competition of local firms, but stimulates affiliate sales to third countries. For example, Antràs and Caballero (2009) show that trade and capital flows may be complements in classical trade theory under financial frictions. Antràs, Desai, and Foley (2009) examine how weak investor protection and financial frictions affect the prevalence of multinational firms and the international financing of investment.
} 
The role of market integration for inequality has been addressed in a number of literatures. In finance, for example, Acemoglu and Zillibotti (1997) as well as Martin and Rey (2004) argue that rich countries have more developed financial markets providing better diversification and thus higher investment levels. This mechanism contributes to a widening gap between rich and poor countries. Matsuyama (2004) develops an overlappinggenerations model with credit market imperfection and investment. He shows that financial markets may cause inequality as symmetric equilibria become unstable and regions separate into rich and poor. An early example from the growth literature is Krugman (1981) pointing out that a difference in capital-labor ratios magnifies due to capital accumulation over time. This process contributes to more inequality between regions. Yet, the empirical evidence suggests that there is a negative correlation between financial market development and income inequality (see e.g. Clarke, Xu, and Zou, 2003; Liang, 2006; Beck, Demirgüç-Kunt, Levine, 2007). We highlight an effect of financial markets on income inequality that works via goods trade and yields predictions that are consistent with the negative correlation between financial market development and income inequality identified in the empirical literature. ${ }^{3}$

There is also a large literature on trade and labor that studies the role of trade liberalization for wage inequality between workers with different skills and even within groups having the same skills (Felbermayr, Prat and Schmerer, 2011, Egger and Kreickemeier, 2008, 2012, Helpman and Itskhoki, 2010, and Helpman, Itskhoki, and Redding, 2010). Finally, it is by now well-understood how trade liberalization affects the migration decision of production factors in the context of international goods trade (Krugman, 1991, and Krugman and Venables, 1995). None of these papers focuses on the role of financial frictions and in particular none of the previous studies accounts for the interaction between trade integration and financial market development which is at the heart of our paper. ${ }^{4}$

The paper is organized as follows. In the next section, we introduce a model of trade, labor mobility, and credit constraints. In Section 3, we derive equilibrium conditions and

\footnotetext{
${ }^{3}$ In a working paper version of this paper, we provide empirical evidence for a negative relationship between financial market development and and the concentration of economic activity across European regions. This finding is consistent with our model and suggests that financial markets play a decisive role for location decisions of firms (see von Ehrlich and Seidel, 2013a).

${ }^{4} \mathrm{~A}$ recent example of moral hazard and factor mobility, but without credit rationing, is Hakenes and Kranich (2010). Credit constraints affect the pattern of agglomeration simply through a cost effect while our model features complex selection effects altering average industry productivity, the number of firms as well as the share of exporters. This turns out essential for the equilibrium distribution of economic activity. Finally, our model entails a richer set of economic motives that drive the location decision of workers.
} 
solve the model. In section 4 we analyze the effects of financial market development on the location of economic activity and the distribution of income across regions. Section 5 concludes with a summary of the main findings and implications for regional policy.

\section{The model}

Consider two regions $i$ and $j$ that are endowed with immobile low-skilled $(L)$ and mobile high-skilled workers $(H)$. Both regions are identical ex ante, but may differ ex post due to migration of high-skilled workers. This gives rise to an endogenous allocation of industries across space (see Krugman, 1991). Unless otherwise stated, we report expressions for region $i$ stressing that similar equations exist for region $j$.

\subsection{Preferences and demand}

Individuals derive utility from consuming two goods, a homogeneous good $Y$ and a differentiated commodity $Q$, where the level of utility is determined by

$$
U_{i}=Q_{i}^{\alpha} Y_{i}^{1-\alpha}
$$

The differentiated good is composed of a mass $V$ of varieties $v$ that are aggregated according to $Q_{i}=\left(\int_{v \in V} q_{i}(v)^{\frac{\sigma-1}{\sigma}} d v\right)^{\frac{\sigma}{\sigma-1}}$. Note that $V$ is determined endogenously in general equilibrium and $\sigma$ represents the constant elasticity of substitution between any two varieties. Further, $q_{i}(v)$ describes the consumption level of variety $v$ in region $i$ - which may be a local or an imported type.

Maximizing (1) subject to the budget constraint delivers total demand for a variant of the differentiated commodity

$$
q_{i}(v)=\frac{p_{i}(v)^{-\sigma}}{P_{i}^{1-\sigma}} \alpha E_{i}
$$

where $P_{i}=\left[\int_{v \in V} p_{i}(v)^{1-\sigma} d v\right]^{1 /(1-\sigma)}$ denotes the price index, $p_{i}(v)$ represents the consumer price for variety $v$ in country $i$ and $E_{i}$ is individual expenditure for consumption (which is equal to income). With Cobb-Douglas preferences, each individual spends a constant income share on each good such that $Q_{i}=\alpha E_{i} / P_{i}$ and $Y_{i}=(1-\alpha) E_{i} / P_{Y i}$. 
Plugging these demand functions into (1) yields indirect utility

$$
W_{i}=\frac{\alpha^{\alpha}(1-\alpha)^{1-\alpha} E_{i}}{P_{i}^{\alpha} P_{Y i}^{1-\alpha}} .
$$

\subsection{Technology and organizational choice}

The homogeneous good is sold in a perfectly competitive market and requires low-skilled labor as the only input. We assume that one unit of low-skilled labor is required to produce one unit of output. Choosing $Y$ as the numéraire and imposing zero trade costs across borders implies that the price for $Y$ is equal to unity in both regions and so are wages of low-skilled workers.

The manufacturing sector is characterized by monopolistic competition using highskilled workers as the only factor of production. Fixed production costs generate increasing returns to scale such that each company exclusively manufactures one commodity for the market. High-skilled workers have the choice between founding a firm (and becoming an entrepreneur) and working as an employee. However, the productivity level of the firm, $\varphi$, is not known ex ante so that in equilibrium workers are indifferent between earning the expected payoff from becoming an entrepreneur and the observed wage rate. As long as the expected payoff is greater than the observed wage rate there will be a highskilled worker who finds it profitable to participate in the lottery to become an active entrepreneur. A high value of $\varphi$ implies a low number of workers $h_{i}$ to produce one unit of output, $q_{i}(\varphi)=\varphi h_{i}$. Further, high-productive firms earn strictly higher profits than low-productive firms (which we show formally below). We follow the literature on heterogeneous firms by assuming that $\varphi$ follows a commonly-known distribution function of the Pareto type, that is $G(\varphi)=1-\varphi^{-k}$, where $k$ captures the shape parameter. We have further normalized the scale parameter to one to simplify notation.

High-skilled workers have an incentive to participate in the productivity lottery as long as expected firm profits exceed their opportunity costs, that is the wage rate $w_{i}$ they could earn as an employee in the manufacturing industry. ${ }^{5}$ This builds on the assumption that entrepreneurs cannot seek employment in one of the manufacturing firms once they have decided to establish a firm. ${ }^{6}$ If their obtained productivity level implies profits, they start

\footnotetext{
${ }^{5}$ We derive this condition formally below.

${ }^{6}$ Egger and Kreickemeier (2012) make a similar assumption.
} 
producing. If $\varphi$ is too low, they exit again and end up without income. ${ }^{7}$

Those entrepreneurs with sufficiently high productivity choose between two organizational modes. They can either solely serve domestic consumers or decide to produce for the export market in addition. We refer to the former type as domestic firms (superscript $d$ ) and to the latter firm type as exporting firms (superscript $x$ ). Both organizational forms imply different levels of fixed costs. To serve consumers domestically, companies need to incur $f^{d}$ units of high-skilled labor while exporting requires an additional fixed investment of the same factor so that $f^{x}>f^{d}$. Shipping goods to the other region is subject to iceberg transport costs implying that $\tau>1$ units of the final good have to be sent for one unit to arrive at the final destination abroad. The choice between domestic sales only and additional exporting is governed by profits of each of these activities which we derive in subsection 2.4 below.

\subsection{Credit market}

Firms crucially rely on external finance to start their operations. In particular, we assume that companies need to secure external finance for fixed costs while variable costs can be covered from revenues. Credit is provided by a perfectly-competitive banking sector. If a high-skilled worker has chosen to become an entrepreneur and to found a domestic firm, she needs $f^{d} w_{i}$ of external finance. If she chooses an exporting type, she requires $f^{x} w_{i}$. Writing a financial contract on these fixed investments implies asymmetric information between the lender and the borrower. In particular, we assume that banks cannot observe the chosen effort level of the entrepreneur. Following Holmstrom and Tirole (1997), the entrepreneur can choose to behave diligently implying a probability of making profits of $\psi_{b}<1$. Alternatively, she can opt for shirking which reduces the probability of making profits to $0<\psi_{s}<\psi_{b}$, but promises private benefits $B w_{i}$ that we express in terms of high-skilled wages. ${ }^{8}$ As the lender can neither observe the chosen effort level nor proof ex post whether the manager has shirked, financial contracts are subject to a moral-hazard problem. We assume that both agents are risk neutral. The entrepreneurs who do not succeed in making profits are hit by a stochastic shock which forces them to exit before

\footnotetext{
${ }^{7}$ One could modify this setting by assuming that entrants only need to invest a fraction of their opportunity $\operatorname{cost} w$ to find out their productivity level. This would leave them with a fraction of market wages, but does not affect the key insights.

${ }^{8}$ Alternatively, we could denote private benefits in terms of the numéraire which would not affect results qualitatively. However, our specification yields less complex expressions enhancing readability.
} 
entering production. While the probability of being hit by the bad shock can be reduced from $1-\psi_{s}$ to $1-\psi_{b}$ by diligent behavior, it is equally distributed across productivities.

Provided the borrower works with high effort, the lender is only willing to grant the loan if the expected payoff from doing so covers the principal. Denoting by $R_{i}^{\ell}$ the repayment to the bank for a loan to a domestic firm $(\ell=d)$ and an exporting firm $(\ell=x)$, respectively, we can express the zero-profit condition for the lenders as

$$
\psi_{b} R_{i}^{\ell}=f^{\ell} w_{i}
$$

The rate of return $\rho$ of such an investment is given by $R_{i}^{\ell}=(1+\rho) f^{\ell} w_{i}$. Combining both equations delivers $1+\rho=1 / \psi_{b}$. As $\psi_{b}<1, \rho$ is strictly positive reflecting a risk premium that compensates for credit default of unsuccessful firms.

To avoid losses from lending, the bank has to make sure that the expected income of the entrepreneur is sufficiently high so that she can repay the principal plus the risk premium. We assume that the marginal firm only has a positive net present value if the entrepreneur behaves. Hence, the bank has to rule out shirking by allowing a sufficiently high income to the entrepreneur. We refer to this condition as the incentive compatibility constraint (IC). For domestic firms, this is given by

$$
\psi_{b}\left[\frac{r_{i}^{\ell}\left(\varphi_{i}\right)}{\sigma}-R_{i}^{\ell}\right] \geq \psi_{s}\left[\frac{r_{i}^{\ell}\left(\varphi_{i}\right)}{\sigma}-R_{i}^{\ell}\right]+B w_{i}
$$

The term in brackets denotes the income of the entrepreneur, that is the difference between operating profits $r_{i}^{\ell}(\varphi) / \sigma$ and the repayment to the bank $R_{i}^{\ell}$ where operating profits are strictly increasing in productivity. Hence, the entrepreneur can pledge only a fraction of her income to the lenders without violating the incentive compatibility constraint, namely $r_{i}^{\ell}(\varphi) / \sigma-B w_{i} / \Delta \psi$, where we have defined $\Delta \psi \equiv \psi_{b}-\psi_{s}$. Firms with a higher productivity than the marginal firm may earn expected profits that suffice to repay the principal even under shirking. But as diligent behavior implies strictly higher expected profits, shirking is never an appealing option for these entrepreneurs. ${ }^{9}$

To ensure zero profits of banks, the expected pledgeable income must not fall short of the principal. We refer to this condition as the participation constraint (PC) which can

\footnotetext{
${ }^{9}$ Since the marginal firm that meets $(I C)$ cannot repay the principal plus risk premium under shirking, firms that are capable of doing so must have greater operating profits than the marginal firm. This in turn implies a higher pledgeable income without violating $(I C)$.
} 
be expressed as

$$
\psi_{b}\left[\frac{r_{i}^{\ell}(\varphi)}{\sigma}-\frac{B w_{i}}{\Delta \psi}\right] \geq f^{\ell} w_{i}
$$

We observe from $(P C)$ that banks are only willing to allow a credit if the entrepreneur generates expected operating profits that cover at least $\psi_{b} B w_{i} / \Delta \psi+f^{\ell} w_{i}$. As operating profits increase in productivity (which we show in the following subsection), only more productive companies receive external finance. In contrast to a world without moral hazard, some entrepreneurs are unable to secure external funding to pay for fixed costs because they cannot commit to behave diligently. Even if they offered a higher risk premium to the lender, the bank would not grant the loan as the remaining income of the entrepreneur would be too low to meet the incentive compatibility constraint. Hence, entrepreneurs who do not meet $(P C)$ due to a too low productivity level cannot start producing and thus end up with no income. As entrepreneurs are able to raise funds from a perfectly competitive banking sector, those that satisfy $(P C)$ offer the lowest possible claim to the lender that meets $(I C)$, that is $R_{i}^{\ell}=f^{\ell} w_{i}(1+\rho){ }^{10}$ This result shows that the entrepreneur receives the entire surplus if the project is funded.

The model features two determinants of credit constraints: Firm productivity and agency costs. First, firms are more likely to receive outside finance if they are more productive and thus larger. As profits strictly increase in $\varphi$, more productive firms leave the entrepreneur with a higher income inducing her to behave. Second, agency costs determine the entrepreneurs' ability to borrow. These costs are determined by a combination of private benefits and the success probabilities under diligence and shirking and can be measured by $c w_{i}$, where we introduce the agency cost parameter $c \equiv \psi_{b} B / \Delta \psi$ on which we rely repeatedly in the subsequent analysis. We observe from $(P C)$ that this term captures the non-pledgeability of income. The higher the value, the more difficult it is to secure external finance for a given level of expected operating profits. With respect to the first component of agency costs, a higher level of private benefits $B w_{i}$ requires a higher income of the entrepreneur to make diligent behavior more attractive than shirking. The second part of agency costs comprises the inverse of the likelihood ratio $\Delta \psi / \psi_{b}$. According to Tirole (2006), the likelihood ratio measures the reduction in the probability of success if the entrepreneur decides to shirk which can also be interpreted as the marginal productivity of behaving diligently. As lenders can infer better the behavior of borrowers at a high

\footnotetext{
${ }^{10}$ Her income is then given by $r_{i}^{\ell}(\varphi) / \sigma-f^{\ell} w_{i}(1+\rho) \geq B w_{i} / \Delta \psi$ which is a reformulation of $(I C)$.
} 
likelihood ratio, it is easier for entrepreneurs to get access to external finance in this case. This definition of agency costs is our key measure of the severeness of credit constraints. We understand a reduction of this friction as the basis for financial development. It is commonly understood that "the agency cost is influenced not only by the project's and the entrepreneur's characteristics, but also by the surrounding legal, regulatory, and corporate environment" (Tirole, 2006, p.118). ${ }^{11}$

\subsection{Profits}

We now derive profits of both domestic firms $(\ell=d)$ and exporting firms $(\ell=x)$ that govern the entrepreneurs' choice of firm types. As firms face a constant price elasticity of demand, profit-maximizing prices are chosen as constant mark-ups over variable costs. For domestic sales and exports, we respectively have

$$
p_{i i}(\varphi)=\frac{\sigma w_{i}}{(\sigma-1) \varphi} \quad p_{i j}(\varphi)=\frac{\sigma \tau w_{i}}{(\sigma-1) \varphi}
$$

where the first subscript always refers to the place of production and the second subscript to the place of sale. Revenues and profits for each market are given by

$$
\begin{array}{ll}
r_{i i}(\varphi)=\frac{p_{i i}(\varphi)^{1-\sigma}}{P_{i}^{1-\sigma}} \alpha E_{i} & r_{i j}(\varphi)=\frac{p_{i j}(\varphi)^{1-\sigma}}{P_{j}^{1-\sigma}} \alpha E_{j} \\
\pi_{i i}(\varphi)=r_{i i}(\varphi) / \sigma-f^{d} w_{i}(1+\rho) & \pi_{i j}(\varphi)=r_{i j}(\varphi) / \sigma-\left(f^{x}-f^{d}\right) w_{i}(1+\rho),
\end{array}
$$

where we have accounted for the risk premium firms need to pay on their fixed costs. Since each surviving firm has to earn at least $B w_{i} / \Delta \psi$ plus the respective fixed costs $f^{\ell} w_{i}(1+\rho)$, the decision to become an exporter is affected by the moral-hazard problem only to the extent that the additional fixed costs $\left(f^{x}-f^{d}\right) w_{i}(1+\rho)$ have to be financed externally (including the risk premium). As long as operating profits from exporting do not fall short of the extra credit costs, it pays for an entrepreneur to export. We derive the export productivity cutoff $\varphi_{i j}^{*}$ by using the condition $\pi_{i}^{x}\left(\varphi_{i j}^{*}\right)=\pi_{i}^{d}\left(\varphi_{i j}^{*}\right)$ which is equivalent to

$$
\frac{r_{i j}\left(\varphi_{i j}^{*}\right)}{\sigma}=\left(f^{x}-f^{d}\right) w_{i}(1+\rho) .
$$

\footnotetext{
${ }^{11}$ See also La Porta, Lopez-de-Silanes, Shleifer, and Vishny (1997).
} 
Hence, an entrepreneur with productivity draw $\varphi_{i j}^{*}$ is indifferent between paying the higher fixed costs $f^{x}$ to become an exporter and paying the lower fixed costs $f^{d}$ to serve only the domestic market. Every entrepreneur with productivity draw beyond $\varphi_{i j}^{*}$ decides to set up an exporting firm. Note that the participation constraint (PC) is always met for an entrepreneur who drew a productivity $\varphi>\varphi_{i j}^{*}$ and accordingly decides to establish an exporting firm. ${ }^{12}$

\section{Equilibrium}

To determine equilibria, we proceed as follows. We first assume that both regions are able to trade both goods while high-skilled workers are immobile. We refer to this case as the short-run. In a second step, we derive the long-run equilibrium where high-skilled workers choose their region of residence and employment based on real wages. We discuss both cases sequentially in the following two subsections.

\subsection{Immobile workers}

To describe the equilibrium, we need to derive the productivity cutoff $\varphi_{i i}^{*}$, that is the productivity level of the least efficient (marginal) producer, as well as equilibrium wages and the number of firms.

Domestic productivity cutoff. To obtain $\varphi_{i i}^{*}$, we combine the free-entry condition $(F E)$ with the marginal-credit-access condition $(M C A)$. In contrast to Melitz (2003), $M C A$ substitutes for the zero-cutoff profit condition because the marginal firm in our model is determined by getting access to external finance rather than by zero profits. Here, the marginal firm earns strictly positive profits in the presence of moral hazard.

High-skilled workers enter the industry as entrepreneurs until expected profits equal entry costs, that is their opportunity cost from working as an employee in the $Q$-sector, $w_{i}$. Formally, this condition reads:

$$
\psi_{b}\left(\varphi_{i i}^{*}\right)^{-k} \bar{\pi}_{i}=w_{i}
$$

\footnotetext{
${ }^{12}$ Under exporting, operating profits are $r_{i}^{x}(\varphi) / \sigma=r_{i}^{d}(\varphi) / \sigma+r_{i j}(\varphi) / \sigma$ while fixed costs become $w_{i}(1+$ $\rho)\left[f^{d}+\left(f^{x}-f^{d}\right)\right]$ such that the participation constraint reads $\psi_{b}\left[r_{i}^{d}(\varphi) / \sigma+r_{i j}(\varphi) / \sigma-B w_{i} / \Delta \psi\right] \geq w_{i} f^{x}$. Accordingly, if (PC) is fulfilled for the domestic firm type it must be fulfilled for the exporting firm type as well because $\varphi>\varphi_{i j}^{*}$ from (5).
} 
The left-hand side describes average profits from domestic sales and exporting conditional on surviving in competition, $1-G\left(\varphi_{i i}^{*}\right)=\left(\varphi_{i i}^{*}\right)^{-k}$, and not being hit by the exogenous shock of failure $\psi_{b}$. Surviving firms can expect to earn $\pi_{i i}\left(\tilde{\varphi}_{i i}\right)$ domestically and $\left(\varphi_{i i}^{*} / \varphi_{i j}^{*}\right)^{k} \pi_{i j}\left(\tilde{\varphi}_{i j}\right)$ from exports where $\left(\varphi_{i i}^{*} / \varphi_{i j}^{*}\right)^{k}$ reflects the probability of becoming an exporter conditional on being active in the domestic market. Further, $\tilde{\varphi}_{i i}$ and $\tilde{\varphi}_{i j}$ represent average productivity levels of all operating firms and those that export, respectively. Due to the Pareto distribution, $\tilde{\varphi}_{i i} / \varphi_{i i}^{*}=\tilde{\varphi}_{i j} / \varphi_{i j}^{*}=[k /(k-\sigma+1)]^{1 /(\sigma-1)}$ holds as a constant relationship between average and cutoff productivities. ${ }^{13}$

It is convenient to express the probability of exporting in terms of domestic productivity cutoffs only. To do this, we derive operating profits of the marginal firm that secures external finance. From the participation constraint $(P C)$ we get

$$
\frac{r_{i i}\left(\varphi_{i i}^{*}\right)}{\sigma}=f^{d} w_{i}(1+\rho)+B w_{i} / \Delta \psi
$$

Entrepreneurs with a productivity draw below $\varphi_{i i}^{*}$ will not obtain credit and accordingly do not succeed in setting up their firm. Using (6) jointly with (5) and $r_{j i}\left(\varphi_{j i}^{*}\right)=$ $r_{i i}\left[\left(\varphi_{j i}^{*} w_{i}\right) /\left(\tau w_{j}\right)\right]$, we can establish the following link between the export cutoff in $j$ and the domestic cutoff in $i$ :

$$
\varphi_{j i}^{*}=\tau\left(\frac{f^{x}-f^{d}}{f^{d}+c}\right)^{\frac{1}{\sigma-1}}\left(\frac{w_{j}}{w_{i}}\right)^{\frac{\sigma}{\sigma-1}} \varphi_{i i}^{*} .
$$

Recall that the agency cost parameter $c$ measures the severeness of the credit constraint. It is immediate that an increase in foreign wages lowers the export cutoff ceteris paribus. Domestic firms become relatively more competitive and more firms export. To ensure that exporting firms also serve local consumers, we restrict the parameter space to $\left(f^{x}-\right.$ $\left.f^{d}\right) /\left(f^{d}+c\right)>1 .^{14}$ It is thus evident that the conditional export probability is limited to range between zero and unity. Taking region $i$ 's export cutoff based on (7), we can

\footnotetext{
${ }^{13}$ For deriving the average productivity we assume $k>\sigma-1$. Technically, this is to ensure that the integral over the productivities converges and represent a standard assumption in the literature on trade and heterogeneous firms.

${ }^{14}$ Note that for symmetric regions $w_{i}=w_{j}$ and $\varphi_{i i}^{*}=\varphi_{j j}^{*}$ such that $\varphi_{j i}^{*}>\varphi_{i i}^{*}$ implies $\varphi_{j i}^{*}>\varphi_{j j}^{*}$ and $\varphi_{i j}^{*}>\varphi_{j j}^{*}$ implies $\varphi_{i j}^{*}>\varphi_{i i}^{*}$. For the general case with asymmetric regions, requiring that firms also serve the domestic market when exporting - i.e. $\varphi_{j i}^{*}>\varphi_{i i}^{*}$ and $\varphi_{i j}^{*}>\varphi_{j j}^{*}$-imposes a limit on relative wages in the two regions. The necessary and sufficient conditions for ensuring that only domestically active firms start exporting are derived in Appendix C.
} 
formulate the conditional export probability as

$$
\left(\frac{\varphi_{i i}^{*}}{\varphi_{i j}^{*}}\right)^{k}=\tau^{-k}\left(\frac{f^{d}+c}{f^{x}-f^{d}}\right)^{\frac{k}{\sigma-1}}\left(\frac{w_{j}}{w_{i}}\right)^{\frac{\sigma k}{\sigma-1}}\left(\frac{\varphi_{i i}^{*}}{\varphi_{j j}^{*}}\right)^{k}
$$

For symmetry, we can infer that the conditional export probability is decreasing in $f^{x}-f^{d}$ and $\tau$ while it is increasing in $f^{d}$ as well as in the agency cost parameter $c$. Further, a higher relative wage in region $j$ reduces that regions competitiveness such that exporting for firms based in region $i$ becomes more likely.

Let us now proceed to the marginal-credit-access condition $(M C A)$. The participation constraint $(P C)$ pins down operating profits of the marginal firm that survives in the domestic market as stated in (6). This allows us to express average profits as a function of domestic cutoff productivity levels. We label this equation the marginal-credit-access condition which is given by 15

$$
\bar{\pi}_{i}=\frac{(1+\rho) w_{i}}{k-\sigma+1}\left\{k c+(\sigma-1)\left[f^{d}+\tau^{-k}\left[\frac{\left(f^{d}+c\right)^{k}}{\left(f^{x}-f^{d}\right)^{k-\sigma+1}}\right]^{\sigma-1}\left(\frac{w_{j}}{w_{i}}\right)^{\frac{\sigma k}{\sigma-1}}\left(\frac{\varphi_{i i}^{*}}{\varphi_{j j}^{*}}\right)^{k}\right]\right\} .
$$

As is evident from $(M C A)$ average profits ceteris paribus increase in $c$. This is because a more severe credit constraint prevents less profitable firms from securing external finance and thus entering the market. Using $(F E)$ and $(M C A)$ for each region delivers two equations that can be solved for the domestic cutoff in $i,{ }^{16}$

$$
\varphi_{i i}^{*}=\left[\frac{\gamma(\sigma-1)}{k-\sigma+1} \frac{1-\phi^{2}}{1-\phi\left(\frac{w_{j}}{w_{i}}\right)^{\frac{\sigma k}{\sigma-1}}}\right]^{\frac{1}{k}}
$$

where we have defined $\gamma \equiv c k /(\sigma-1)+f^{d}$ and $\phi \equiv \tau^{-k}\left(\frac{c+f^{d}}{f^{x}-f^{d}}\right)^{\frac{k-\sigma+1}{\sigma-1}} \frac{\left(c+f^{d}\right)}{\gamma}$. Except for the wage rates, all parameters determining the cutoff productivity are the same for both regions. For symmetric regions, $w_{i}=w_{j}$ and the cutoff is strictly increasing in $c$. This is intuitive as a more severe credit constraint precludes the least productive firms from

\footnotetext{
${ }^{15}$ See Appendix A for further details on the derivation of this condition.

${ }^{16}$ Appendix B provides further details on the derivation of the domestic cutoffs and on the comparative statics.
} 
producing and only the more productive firms remain. Put differently, it requires higher operating profits (which is only possible with a higher $\varphi$ ) to meet $(P C)$. Once regions become asymmetric the cutoffs remain strictly positive in both regions and the region with the higher wage rate features the lower cutoff productivity (see Appendix $\mathrm{C}$ for a formal proof). From the participation constraint the latter seems surprising as we would expect more firms to be truncated for higher fixed costs. Yet, there is a countervailing effect which follows from the free-entry condition: Facing higher wages than the foreign region reduces competitiveness and thus average profits which ceteris paribus has to be compensated by a higher probability to survive the lottery, that is by a lower cutoff productivity.

Wages and the number of firms. So far, the discussion was based on a thought experiment with fixed wages. However, both wages and the number of firms in each country, $M_{i}$ and $M_{j}$ adjust endogenously in general equilibrium. Accordingly, to obtain these variables for the general case of an asymmetric allocation of high-skilled workers across regions, we need to employ the respective labor-market-clearing conditions ( $L M C)$ jointly with goods-market-clearing equations $(G M C)$. Let us denote by $L$ the global stock of low-skilled workers which are distributed symmetrically across both regions such that $L_{i}=L_{j}=L / 2$. The global stock of high-skilled workers is denoted by $H=H_{i}+H_{j}$ and $\lambda$ represents their share residing in region $i$. Expressing the number of exporters and the number of entrants in each region respectively as $M_{i j}=\left(\varphi_{i i}^{*} / \varphi_{i j}^{*}\right)^{k} M_{i}$ and $M_{i e}=$ $\left(\varphi_{i i}^{*}\right)^{k} M_{i} / \psi_{b}$, we can formulate the market-clearing condition for high-skilled workers in region $i$ as ${ }^{17}$

$$
\lambda H=M_{i}\left[\frac{q_{i i}\left(\tilde{\varphi}_{i i}\right)}{\tilde{\varphi}_{i i}}+\frac{f^{d}}{\psi_{b}}\right]+\left(\frac{\varphi_{i i}^{*}}{\varphi_{i j}^{*}}\right)^{k} M_{i}\left[\frac{q_{i j}\left(\tilde{\varphi}_{i j}\right)}{\tilde{\varphi}_{i}}+\frac{f^{x}-f^{d}}{\psi_{b}}\right]+\left(\varphi_{i i}^{*}\right)^{k} \frac{M_{i}}{\psi_{b}} .
$$

Labor demand on the right-hand side of $(L M C)$ has three components. (i) The first component captures variable and fixed labor inputs of all firms in country $i$ that produce for the domestic market plus the fixed inputs of firms that were hit by the bad shock. (ii) The second component refers to the additional labor inputs needed to serve the export market following the same logic. (iii) Finally, some high-skilled workers have chosen to become entrepreneurs which is captured by the last term. A fraction of these entrants is not productive enough and has never applied for a loan while another fraction has secured

\footnotetext{
${ }^{17}$ The number of entrants corresponds to the number of workers who want to become an entrepreneur. Only $\varphi_{i i}^{*} \psi_{b}$ of those will eventually become an active entrepreneur.
} 
external finance but was hit by the bad shock before production started. Both groups end up with no income.

Next, we introduce the goods-market-clearing condition which equates net exports of manufactured varieties with net imports of the homogeneous good. The latter is the difference between local expenditure for the homogeneous good and local production of that good. For region $i$, this can be expressed as $(1-\alpha)\left[L / 2+\lambda H w_{i}\right]-L / 2$ such that the goods-market-clearing condition reads: ${ }^{18}$

$$
(1-\alpha) \lambda H w_{i}-\alpha L / 2=\left(\frac{\varphi_{i i}^{*}}{\varphi_{i j}^{*}}\right)^{k} M_{i} r_{i j}\left(\tilde{\varphi}_{i j}\right)-\left(\frac{\varphi_{j j}^{*}}{\varphi_{j i}^{*}}\right)^{k} M_{j} r_{j i}\left(\tilde{\varphi}_{j i}\right) .
$$

The left-hand side represents the difference between aggregate revenues from exports in $i$ and $j$. If production in the manufacturing industry is larger in $i$ than in $j$, region $i$ is a net exporter of manufactured goods and a net importer of the homogeneous good. Note that $(L M C)$ and $(G M C)$ are functions of the price index which is given by

$$
P_{i}=\left[M_{i}\left(\frac{\sigma w_{i}}{(\sigma-1) \widetilde{\varphi}_{i i}}\right)^{1-\sigma}+\left(\varphi_{j j}^{*} / \varphi_{j i}^{*}\right)^{k} M_{j}\left(\frac{\tau \sigma w_{j}}{(\sigma-1) \widetilde{\varphi}_{j i}}\right)^{1-\sigma}\right]^{\frac{1}{1-\sigma}}
$$

Similar expressions exist for region $j$ 's labor market and market-clearing such that we can use the four equations to solve for $M_{i}, M_{j}, w_{i}$ and $w_{j}$ for given distribution of high-skilled workers.

\subsection{Endogenous distribution of industry}

We now relax the assumption that high-skilled workers are immobile and allow for an endogenous distribution of manufacturing firms across countries. It is noteworthy that it is not firms that move, but workers. Changing the allocation of labor will result in endogenous adjustments of firms and wages to meet the equilibrium conditions derived in the previous subsection. To describe the long-run equilibrium, we first need to specify the migration equation. High-skilled workers migrate as long as the target region offers higher

\footnotetext{
${ }^{18}$ Note that for goods-market-clearing the value excess demand for $Q$ products in $i$ has to equal the value of excess production of $Q$ in $j, E D_{i}^{Q}=E P_{j}^{Q}$. At the same time, the value of excess demand for $Y$ in $j$ has to equal the value of excess production of $Y$ in $i, E D_{j}^{Y}=E P_{i}^{Y}$. Balanced trade requires with two countries and two sectors that $E P_{j}^{Q}=E P_{i}^{Y}$ such that we obtain $E D_{i}^{Q}=E P_{i}^{Y}$ and $E D_{j}^{Y}=E P_{j}^{Q}$. In our framework the latter immediately yields $(G M C)$.
} 
indirect utility. We compute this value by plugging in the equilibrium outcome of the endogenous variables $M_{i}, M_{j}, w_{i}, w_{j}$ into (3) and calculate the utility differences for the representative mobile laborer in regions $i$ and $j$ for each labor allocation $\lambda$. We identify a migration equilibrium if either (i) indirect utilities of high-skilled workers are equated in both regions, so $W_{i}=W_{j}$, or (ii) all workers and industry have agglomerated in one of the two locations. For interior equilibria, we must have

$$
\frac{w_{i}}{P_{i}^{\alpha}}=\frac{w_{j}}{P_{j}^{\alpha}}
$$

Three forces determine the long-run equilibrium. (i) Firms prefer to locate in the larger market as this promises higher profits in the presence of trade costs (Krugman, 1980). This effect is referred to as the home-market effect and works in favor of allocating the manufacturing industry entirely in one region (due to higher nominal wages). (ii) The second effect is called market-crowding effect and works as a dispersion force. The idea is that - for given market size - firms prefer fewer competitors as this increases their market share and hence profits. To meet the labor-market clearing condition, nominal wages need to fall when competition increases. (iii) Finally, the price-index effect states that mobile workers prefer to live in the region with the lower price index. This is usually the larger region as fewer varieties need to be imported and thus, consumer prices are lower. This effect works in favor of agglomeration. ${ }^{19}$

Like in Krugman (1991), endogenous variables enter in a non-linear fashion such that closed-form solutions are generally infeasible. However, we are able to derive closedform solutions for the symmetric equilibrium with $\lambda=0.5$ and corner solutions with $\lambda=1 \vee \lambda=0 .{ }^{20}$ Moreover, we derive an implicit function that describes the critical level of trade costs below which the symmetric equilibrium becomes unstable (break point). For the general case, we solve the model numerically.

Before we study the role of credit constraints for the location of industry, we solve the model in the absence of credit constraints $(c=0)$ for different values of trade costs. This allows us to document that the economic mechanisms in our model produce the same

\footnotetext{
${ }^{19}$ Note that the mechanism highlighted in our benchmark model works also in more simple versions that do not feature all three forces. For instance, quasi-linear preferences as in Pflüger (2004) or exogenous regional expenditure shares as in Martin and Rogers (1995) would weaken agglomeration forces but the comparative statics with regard to financial market development remain qualitatively the same.

${ }^{20}$ See Appendix D for the symmetric and the corner equilibria.
} 
Figure 1: Trade Costs and Location

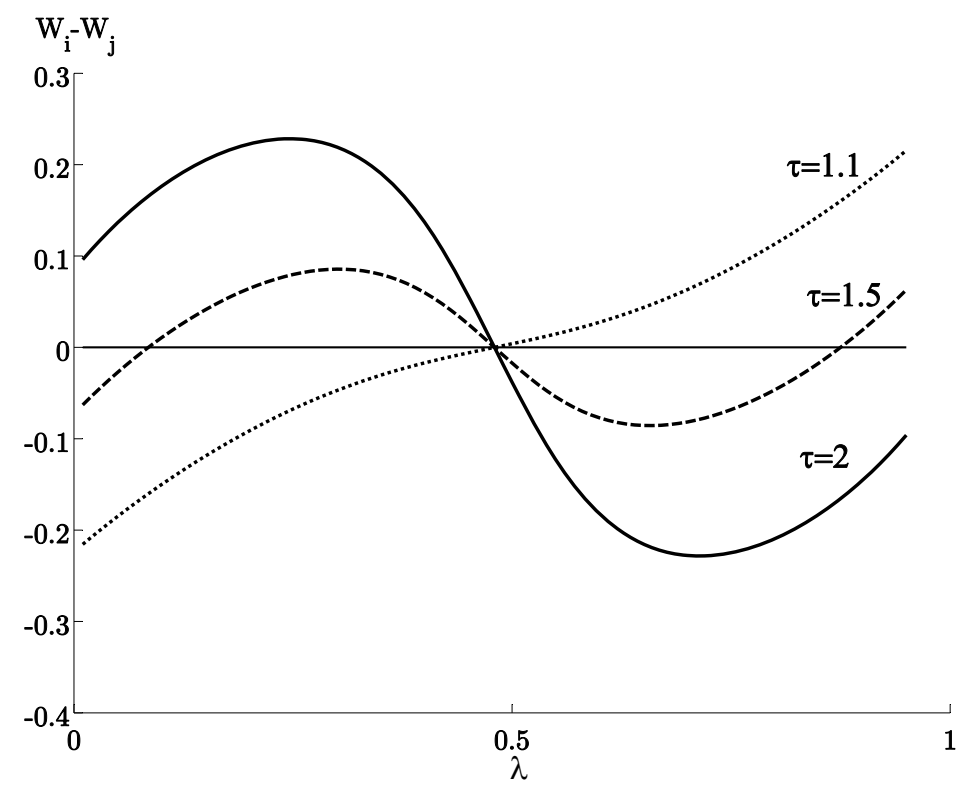

location pattern as in Krugman (1991) - even though he abstracts from heterogeneous firms and export fixed costs. At high levels of trade costs, the symmetric equilibrium with $\lambda=0.5$ is the only stable outcome while corner solutions $(\lambda=1$ or $\lambda=0)$ evolve with low trade barriers. A standard illustration of equilibria in this context is Figure 1 that shows differences in high-skilled workers' indirect utility for each possible labor allocation $\lambda$ and three distinct values of trade costs. ${ }^{21}$ The functions represent equilibria for each level of $\lambda$ when high-skilled workers are assumed to be immobile (short-run). If we allow for mobility (long run), though, interior equilibria are only stable if the slope at $W_{i}-W_{j}=0$ is negative. Otherwise, a deviation from the symmetric equilibrium raises indirect utility in the target region inducing more outmigration until all mobile workers reside in one country.

It is apparent that full agglomeration of the manufacturing industry occurs at low levels of trade costs $(\tau=1.1)$. For an intermediate level of trade costs $(\tau=1.5)$, there are five steady states. However, only the full agglomeration equilibria $(\lambda=0$ and $\lambda=1)$ and

\footnotetext{
${ }^{21}$ For Figures 1,2,4 we choose the following parameter values: $f^{x}-f^{d}=35, k=4, \alpha=0.4$, and $\sigma=3$. All the results are insensitive to the choice of these parameters. In choosing the parameter values we account for the so called 'no-black-hole' condition $(\sigma-1) / \sigma>\alpha$.
} 
the symmetric dispersion equilibrium $(\lambda=0.5)$ are stable. Increasing trade frictions to $\tau=2$ renders dispersion forces dominant such that only $\lambda=0.5$ is a stable equilibrium. ${ }^{22}$

\section{Financial market development}

\subsection{Location equilibria}

Let us now turn to the role of credit constraints for the equilibrium distribution of mobile workers. For this exercise, we keep trade costs constant (at $\tau=1.7$ ) and vary the agency cost parameter instead. In Figure 2 the solid, dashed, and dotted functions depict the short-run equilibria for the $c=0, c=10$, and $c=20$ scenarios where all other parameters are kept constant. A tightening of credit constraints (an increase in $c$ ) leads to an anti-clockwise rotation of $W_{i}-W_{j}$ around $\lambda=0.5$. Figure 2 helps us identify long-run industry location equilibria. In the absence of credit constraints, that is $c=0$, we observe that only the symmetric interior equilibrium is stable. Full agglomeration is unstable. For an intermediate level of credit constraints, $c=10$, five potential equilibria exist: two asymmetric interior, a symmetric interior and two agglomeration equilibria. In contrast to the symmetric interior and the agglomeration equilibria, the asymmetric interior equilibria are not stable. Raising the financial constraints' intensity further to $c=20$ results in a destabilization of the symmetric equilibrium and implies that asymmetric interior equilibria no longer exist. Hence, for sufficiently tight credit constraints the entire manufacturing industry is located in one region.

After we have analyzed the effects of credit constraints for a given level of trade costs we now study the interaction between credit constraints and trade costs. Evaluating the total derivatives of the equilibrium conditions $(L M C)$ and $(G M C)$ at the equilibrium values of the endogenous variables for $\lambda=1 / 2$ enables us to express the parameter constellation for which the symmetric equilibrium becomes unstable analytically. In Appendix D we obtain an implicit solution for the break point $\tau_{B}$ which indicates the critical level of trade costs below which the symmetric equilibrium is unstable. It can be shown that an increase in agency costs leads to a marked increase of the break point $\tau_{B}$. Hence, stable

\footnotetext{
${ }^{22}$ In a recent paper, von Ehrlich and Seidel (2013b) show in more detail that firm heterogeneity does not affect the general pattern of industry location in the Krugman (1991) model: Trade liberalization renders clustering of high-skilled workers in one location more attractive. However, firm heterogeneity leads to full agglomeration already at higher levels of trade costs compared to the homogeneous-firms version.
} 
Figure 2: CRedit Constraints And Location

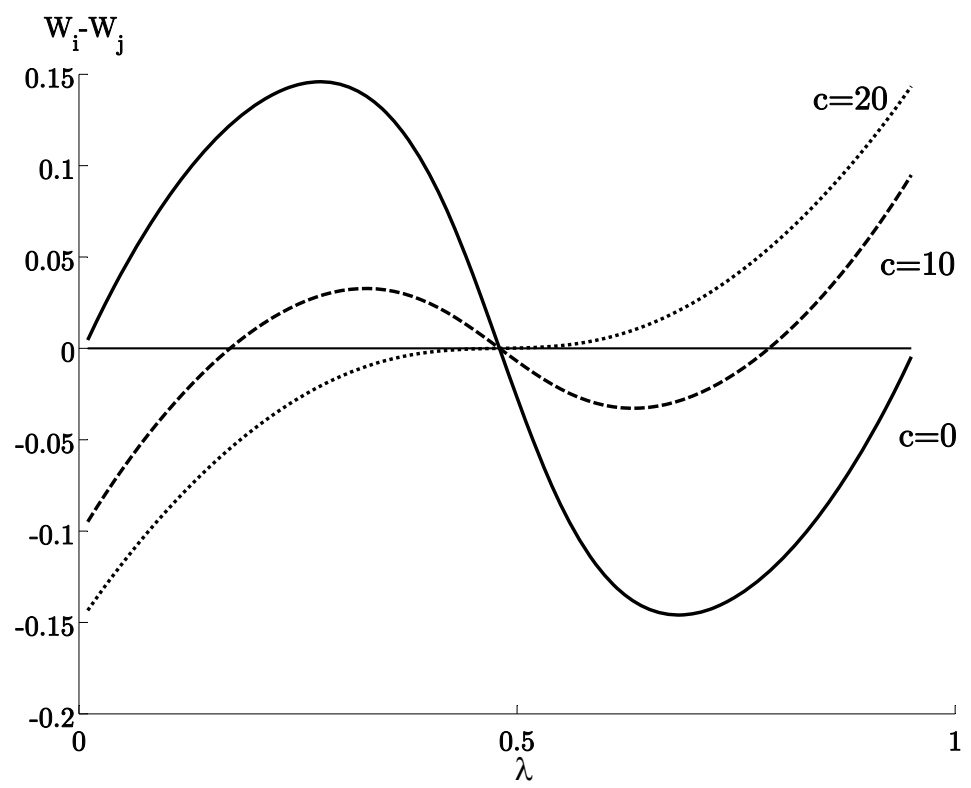

full-agglomeration equilibria occur at a higher level of trade costs when credit constraints are more severe. This indicates that net agglomeration forces must increase in $c$ such that credit constraints stimulate the clustering of industries in one location. Or, alternatively, financial market development establishes an equal distribution of economic activity for a wider range of trade costs. In sum, financial market development and trade liberalization have opposite effects for the location incentives of mobile factors. Besides agency costs, the break point level of trade costs is determined by fixed costs, $f^{\ell}$, the underlying productivity distribution, $k$, and by the expenditure share of the manufacturing sector, $\alpha$. In Figure 3 we illustrate the comparative statics of the break point with respect to these parameters in which we focus on $\tau_{B}(c)$.

In each of the three panels in Figure 3 we plot the break point as a function of the agency cost parameter where the first panel considers different levels of net export fixed costs $f^{x}-f^{d}$, the second panel varies the productivity distribution entrepreneurs draw from, and the third panel highlights the interaction of $\partial \tau_{B} / \partial c$ with the expenditure share of manufacturing products $\alpha$. The $\tau_{B}(c)$ curves display the critical $\tau-c$ combinations where symmetry just starts to become unstable while the areas above and below the individual curves mark $\tau-c$ combinations where symmetry represents a stable and an unstable equilibrium, respectively. 
Figure 3: Comparative Statics of the Break Point

(i) Change in $f^{x}-f^{d}$

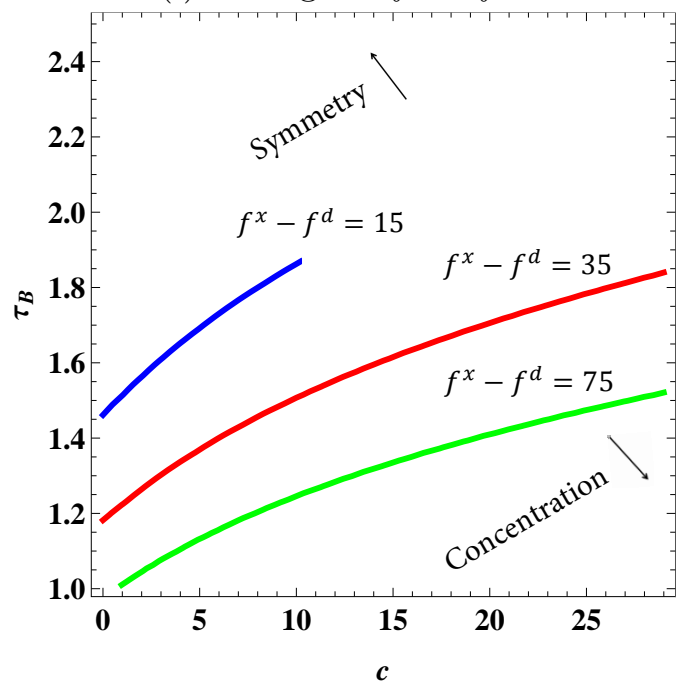

(ii) Change in $k$

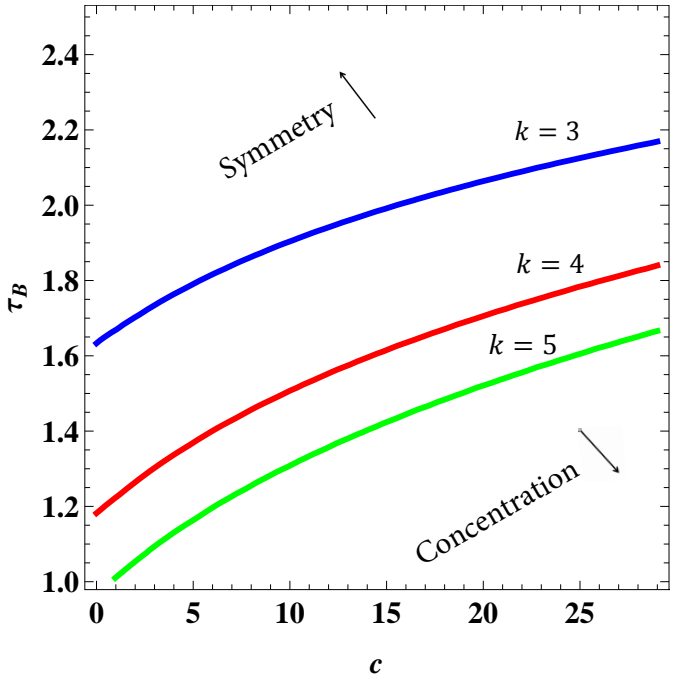

(iii) Change in $\alpha$

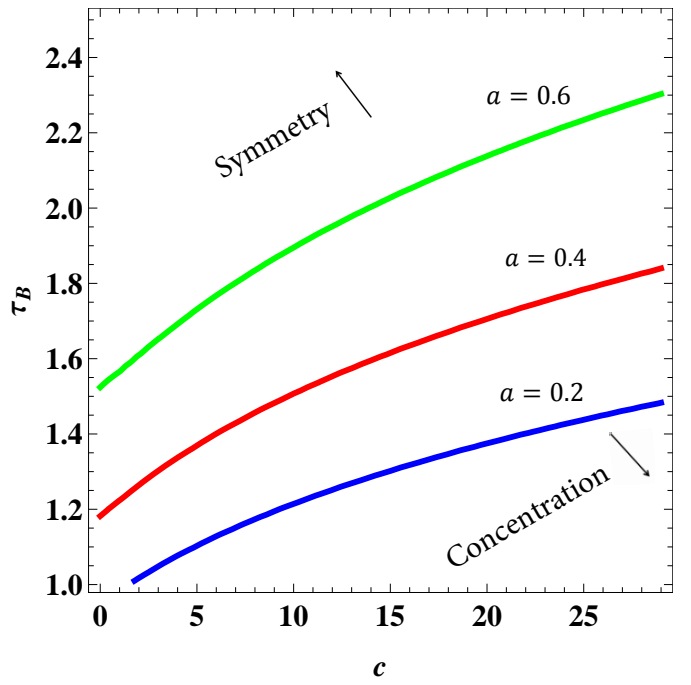

Note: The figures display the break point level of variable trade $\operatorname{costs} \tau_{B}$ as a function of agency costs $c$ for various levels of fixed trade costs $f^{x}-f^{d}$, firm heterogeneity $k$, and expenditure shares of the manufacturing sector $\alpha$. The curves display the critical $\tau-c$ combinations where symmetry just starts to become unstable while the areas above and below the individual curves mark $\tau-c$ combinations where symmetry and full concentration apply in long-run equilibrium, respectively. The functions follow immediately from (D.5) in Appendix D. In each of the plots, the red line corresponds to a benchmark with $k=4, \sigma=3, f^{x}-f^{d}=35$. The green lines correspond to cases where the change-parameter of the respective panel i.e. $f^{x}-f^{d}, k$, or $\alpha$ is higher than in the benchmark while the blue lines mark cases with lower levels than in the benchmark. Note that the parameter space for $c$ is limited to $c<f^{x}-2 f^{d}$ as we require $\varphi_{j i}^{*}>\varphi_{i i}^{*}$. 
First and most importantly, all panels confirm that the break point $\tau_{B}(c)$ is always increasing in agency costs implying that symmetry is stable for high levels of variable trade costs and low levels of agency costs. This illustrates that (symmetric) financial market development (i.e. a reduction in $c$ ) weakens the incentives for high-skilled workers and industries to cluster in one location while trade liberalization implies the opposite. Turning to panel (i), a higher level of net export fixed costs $f^{x}-f^{d}$ reduces ceteris paribus the symmetry breaking level of variable trade costs. This is intuitive as higher export fixed costs reduce the propensity to export according to (8). As argued above, equalizing forces become relatively stronger implying an equal distribution of the manufacturing industry a stable equilibrium for a wider range of trade costs. Alternatively, this relationship is not surprising as in our model effective trade costs consist of a fixed and a variable component which can substitute for each other. Holding agency costs constant the symmetry breaking indirect utility level can either be reached by a relatively high level of export fixed costs in combination with rather low variable trade costs or by a relatively low level of $f^{x}-f^{d}$ in combination with a high level of $\tau$. In panel (ii), we vary the distribution shape parameter $k$ which is a measure of firm heterogeneity. A high value of $k$ implies a lower probability of drawing a high productivity level $\varphi$ leading to less heterogeneity of firm productivities. We see from (8) that the export propensity declines in $k$ such that symmetry-breaking occurs at lower levels of trade costs. ${ }^{23}$ Lastly, we observe from panel (iii) that a larger expenditure share of the manufacturing sector, $\alpha$, corresponds with stronger net agglomeration forces as the $\tau_{B}(c)$ curve is shifted upwards. This link is well understood in the regional economics literature and also present in our framework. ${ }^{24}$ Intuitively, a low expenditure share reduces the size of the home market $\alpha(L / 2+w \lambda H)$ speaking against clustering. Further, the price index responds less sensitively to changes in the allocation of high-skilled workers if prices of manufactured goods have a low weight in the consumption basket.

\subsection{Income inequality}

Let us now turn to the implications for income inequality. In Figure 4, we plot the ratio of real wages in the two regions $W_{i} / W_{j}$ as a function of trade costs for alternative levels of agency costs. While Panel A reports relative wages in the vertical dimension, Panel B offers

\footnotetext{
${ }^{23}$ See von Ehrlich and Seidel (2013b) for a more detailed exposition of firm heterogeneity for location decisions.

${ }^{24}$ See Baldwin, Forslid, Martin, Ottaviano, and Robert-Nicoud (2003) for details.
} 
the bird's-eye perspective to better illustrate the shape of the full-agglomeration surface (low $\tau$ and high $c$ ). The blue color identifies symmetric equilibria where inter-regional incomes are identical while "dark red" captures the equilibria with the most unequal relative wages. Note that we have normalized the total number of low-skilled workers to $L=L_{i}+L_{j}=1-\alpha$ and the total number of high-skilled workers to $H_{i}+H_{j}=\alpha$. This ensures that the nominal wage of $Q$-sector workers equals the agricultural wage in the symmetric and full concentration equilibria. Hence, regional inequality is not simply driven by a concentration of the scarce factor which receives a higher reward on the labor market, but by real wages and the access to product markets.

Let us start from a symmetric equilibrium (blue). If trade costs fall below the break point, the symmetric equilibrium collapses causing a sharp increase in inequality as individuals in $i$ are able to consume more manufactured products at lower costs than in $j$. The two panels A and B nicely illustrate that the break point decreases in financial development (lower $c$ ). Interestingly, the more integrated regions become, the more important is a frictionless capital market for avoiding a divergence in per-capita GDP. This is because for low levels of trade costs already a moderate level of credit constraints yields divergence while for high trade costs even very poor financial market institutions will not break symmetry.

Beyond this insight, Figure 4 further reveals how income inequality changes with trade costs and financial development once clustering of the manufacturing industry has occurred. Generally, smaller distances to the break point imply more inequality. However, a further reduction in trade costs reduces inequality (see Krugman and Venables, 1995) while inequality increases with deeper financial markets (lower $c$ ) on the full-agglomeration surface. This fact is best illustrated in Panel B as we move from dark red to light blue with lower $\tau$ and higher $c$. In the full-agglomeration scenario, financial development raises inequality as the number of firms (and thus product varieties) strictly increases. This effect relies on love-of-variety preferences and is certainly of second-order importance compared to the pronounced jump in inequalities once we move from a symmetric to an asymmetric equilibrium. Importantly, inequality is strictly lower if economic activity is evenly distributed across both regions. 
Figure 4: Per-Capita Income Inequality

\section{Panel A}

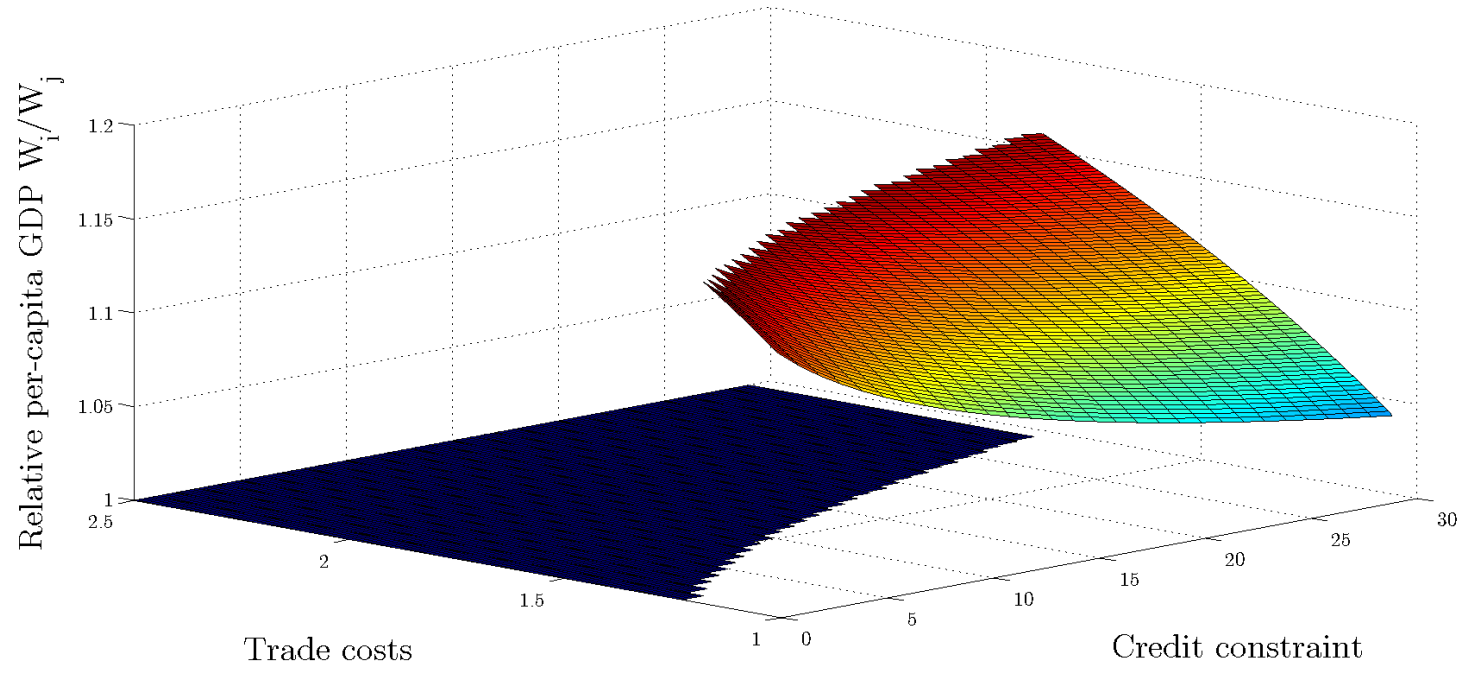

\section{Panel B}

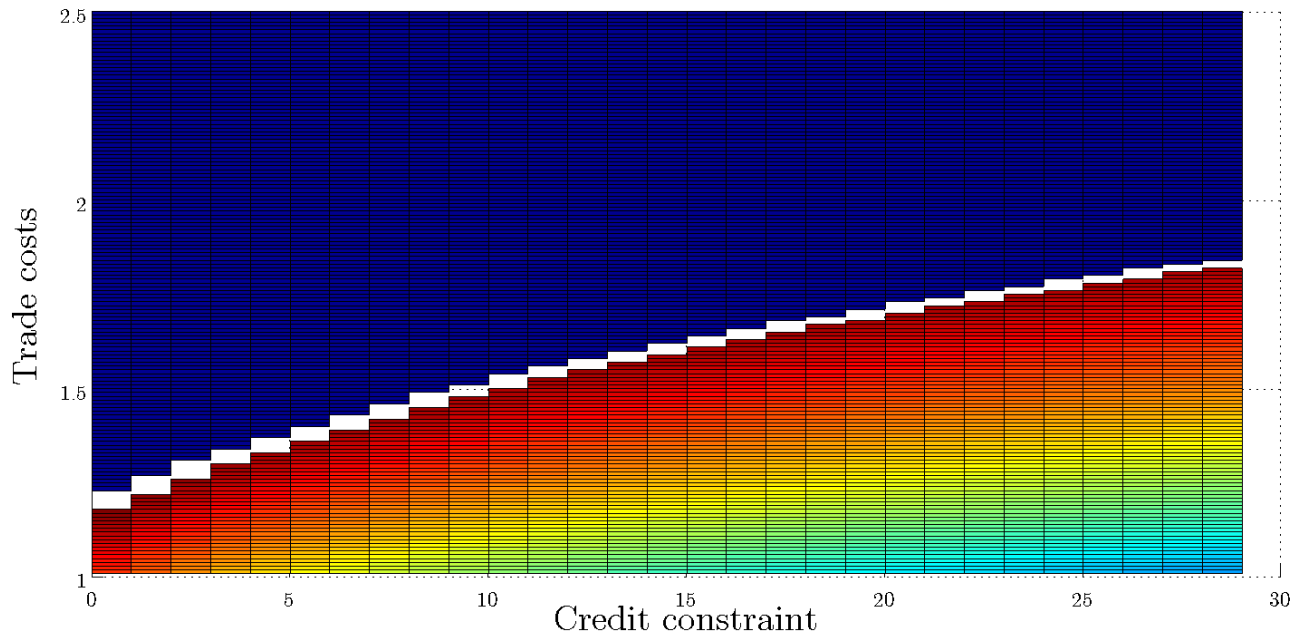

Note: "Blue" marks areas with equal distribution of per-capita GDP across regions and "red" marks areas with very unequal distribution of per-capita GDP. Panel B is a two dimensional representation of the same equilibria illustrated in Panel A. 
We can also make statements about income inequality between high-skilled and lowskilled workers across both regions. It is obvious that a higher inequality between regional GDP must be associated with higher inequality between skill groups as clustering of industry is driven by the agglomeration of high-skilled workers in the core region.

\subsection{Intuition}

What is the intuition behind these effects? Why does financial development have the opposite impact on the location of industry as trade liberalization? As is well understood from the economic geography literature (Krugman, 1991), high trade costs cannot be associated with full agglomeration of manufacturing firms. If markets face little competition from firms in the other market, it always pays off to leave the agglomeration and produce in the periphery to exploit market power. For lower levels of trade costs, the advantages of producing in the larger market dominate. These insights must remain valid even if we endogenize the export propensity. Lower trade barriers not only reduce the consumer price of imported varieties, but also increase the number and share of available products in each market.

In our model, the export propensity is also affected by financial development. We observe from (9) and (7) that agency costs have a greater impact on the domestic productivity cutoff than on the export productivity cutoff. Hence, increasing agency costs eliminate particularly small non-exporter firms. Intuitively, this is because being an exporter implicitly signals to be an entrepreneur with high productivity and thus no incentive to shirk. Such an entrepreneur satisfies the incentive constraint also for higher agency costs. Accordingly, we see from (8) that the share of exporting firms decreases in trade costs and increases in agency costs if both regions are identical, such that $w_{i}=w_{j}$ and $\varphi_{i i}=\varphi_{j j}$. A lower export propensity implies less inter-regional competition such that the agglomeration forces decrease relative to the dispersion forces.

To further improve intuition, let us consider the boundary cases of symmetry and full concentration. With a low share of exporters concentration of the manufacturing industry in one region cannot be a stable situation because the first firm that moves to the periphery will have a quasi-monopoly power there earning very high profits. Hence, the dispersion forces dominate in this case. In contrast, if agency costs are high and only large firms survive this means that almost all firms export. In such a situation firms do not gain 
from moving to the periphery because this does not allow them to avoid competition. Hence, they prefer to cluster and capitalize on the agglomeration benefits due to a larger home market. In this case, the dispersion force is negligible and agglomeration forces dominate. As financial development (a decrease in agency costs) reduces the share of exporters, a symmetric distribution of workers and manufacturing firms turns out to be a stable equilibrium for a wider range of trade costs (see Figure 3).

\section{Concluding remarks}

In this paper, we have developed a model that combines goods trade, labor migration and credit constraints due to moral hazard to study the role of financial market development for the distribution of economic activity and income both across and within regions. We show that better access to external funds reduces the incentives for high-skilled workers to cluster in one region such that economic activity and thus wealth is more equally distributed. This result stands in contrast to previous research in the finance literature where globalization of financial markets was shown to cause more inequality.

In our framework, the effects of financial market development work through integrated product markets. Mitigating credit constraints reduces the export propensity such that clustering of all firms in one location becomes less attractive. An increase of trade barriers would have the same effects. Exporters are not credit-rationed because only very productive, and thus large firms find it profitable to serve customers abroad. Given that these firms also make large profits from domestic sales, their managers have no problem in committing to diligent behavior to secure the loan. In this case, diligent behavior implies a strictly higher income for entrepreneurs.

Our results have important implications for public policies. As politicians are often concerned about regional cohesion, it is crucial to understand the implications of financial market development for the location pattern of industries. In this regard, our paper conveys good news in the sense that lower financial frictions work as a countervailing force to trade integration in reducing the incentive for clustering. Further, deeper financial markets allow for more integrated product markets (that promise welfare gains from trade) without jeopardizing the goal of equal regional living conditions. 


\section{Appendix}

\section{A Deriving the marginal-credit-access condition (MCA)}

Average expected profits accrue from domestic operating profits $r_{i i}\left(\widetilde{\varphi}_{i i}\right) / \sigma$ minus fixed costs for domestic sales and from foreign operating profits $r_{i j}\left(\widetilde{\varphi}_{i j}\right) / \sigma$ minus export fixed costs. The latter have to be weighted by the probability of becoming an exporter conditional on being active in the domestic market. Hence, the average expected profits in region $i$ read

$$
\bar{\pi}_{i}=\frac{r_{i i}\left(\widetilde{\varphi}_{i i}\right)}{\sigma}-f^{d} w_{i}(1+\rho)+\left(\frac{\varphi_{i i}^{*}}{\varphi_{i j}^{*}}\right)^{k}\left[\frac{r_{i j}\left(\widetilde{\varphi}_{i j}\right)}{\sigma}-\left(f^{x}-f^{d}\right) w_{i}(1+\rho)\right] .
$$

Substituting $r_{i i}\left(\widetilde{\varphi}_{i i}\right)=\left(\frac{\widetilde{\varphi}_{i i}}{\varphi_{i i}^{*}}\right)^{\sigma-1} r_{i i}\left(\varphi_{i i}^{*}\right)$ and $r_{i j}\left(\widetilde{\varphi}_{i j}\right)=\left(\frac{\widetilde{\varphi}_{i j}}{\varphi_{i j}^{*}}\right)^{\sigma-1} r_{i j}\left(\varphi_{i j}^{*}\right)$ - which holds because revenues from the respective market differ only with respect to firm-specific productivity - as well as $r_{i i}\left(\varphi_{i i}^{*}\right)=\sigma w_{i}\left[\frac{f^{d}}{\psi_{b}}+\frac{B}{\Delta \psi}\right]$ and $r\left(\varphi_{i j}^{*}\right)=\sigma w_{i} \frac{f^{x}-f^{d}}{\psi_{b}}$ from equations (5) and (6) yields

$\bar{\pi}_{i}=\left[\left(\frac{\widetilde{\varphi}_{i i}}{\varphi_{i i}^{*}}\right)^{\sigma-1}\left(f^{d}+c\right)-f^{d}\right] w_{i}(1+\rho)+\left(\frac{\varphi_{i i}^{*}}{\varphi_{i j}^{*}}\right)^{k}\left[\left(\frac{\widetilde{\varphi}_{i j}}{\varphi_{i j}^{*}}\right)^{\sigma-1}-1\right]\left(f^{x}-f^{d}\right) w_{i}(1+\rho)$.

Note that we have substituted $\psi_{b}=1 /(1+\rho)$ and $c=B /[\Delta \psi(1+\rho)]$. Further substituting the Pareto distribution's characteristics $\widetilde{\varphi}_{i i} / \varphi_{i i}^{*}=\widetilde{\varphi}_{i j} / \varphi_{i j}^{*}=[k /(k-\sigma+1)]^{1 /(\sigma-1)}$, as well as the export probability from equation (8) delivers the average expected profits as stated in equation $(M C A)$.

\section{B Deriving the domestic cutoffs}

Using the marginal-credit-access conditions $(M C A)$ together with the free-entry conditions $(F E)$ yields

$$
\begin{aligned}
& \frac{k-\sigma+1}{\sigma-1}=\left(\varphi_{i i}^{*}\right)^{-k}\left(\frac{c k}{\sigma-1}+f^{d}\right)+\left(\varphi_{j j}^{*}\right)^{-k} \tau^{-k}\left(f^{x}-f^{d}\right)^{\frac{k-\sigma+1}{1-\sigma}}\left(\frac{w_{j}}{w_{i}}\right)^{\frac{\sigma k}{\sigma-1}}\left(f^{d}+c\right)^{\frac{k}{\sigma-1}} \\
& \frac{k-\sigma+1}{\sigma-1}=\left(\varphi_{j j}^{*}\right)^{-k}\left(\frac{c k}{\sigma-1}+f^{d}\right)+\left(\varphi_{i i}^{*}\right)^{-k} \tau^{-k}\left(f^{x}-f^{d}\right)^{\frac{k-\sigma+1}{1-\sigma}}\left(\frac{w_{i}}{w_{j}}\right)^{\frac{\sigma k}{\sigma-1}}\left(f^{d}+c\right)^{\frac{k}{\sigma-1}}
\end{aligned}
$$


for countries $i$ and $j$, respectively. This equation system can be solved for the domestic cutoffs in the two countries:

$$
\begin{gathered}
\left(\varphi_{i i}^{*}\right)^{k}=\frac{\sigma-1}{k-\sigma+1} \frac{\left(\frac{c k}{\sigma-1}+f^{d}\right)^{2}-\left[\tau^{-k}\left(f^{x}-f^{d}\right)^{\frac{k-\sigma+1}{1-\sigma}}\left(f^{d}+c\right)^{\frac{k}{\sigma-1}}\right]^{2}}{\frac{c k}{\sigma-1}+f^{d}-\tau^{-k}\left(f^{x}-f^{d}\right)^{\frac{k-\sigma+1}{1-\sigma}}\left(\frac{w_{j}}{w_{i}}\right)^{\frac{\sigma k}{\sigma-1}}\left(f^{d}+c\right)^{\frac{k}{\sigma-1}}} \\
\left(\varphi_{j j}^{*}\right)^{k}=\frac{\sigma-1}{k-\sigma+1} \frac{\left(\frac{c k}{\sigma-1}+f^{d}\right)^{2}-\left[\tau^{-k}\left(f^{x}-f^{d}\right)^{\frac{k-\sigma+1}{1-\sigma}}\left(f^{d}+c\right)^{\frac{k}{\sigma-1}}\right]^{2}}{\frac{c k}{\sigma-1}+f^{d}-\tau^{-k}\left(f^{x}-f^{d}\right)^{\frac{k-\sigma+1}{1-\sigma}}\left(\frac{w_{i}}{w_{j}}\right)^{\frac{\sigma k}{\sigma-1}}\left(f^{d}+c\right)^{\frac{k}{\sigma-1}}} .
\end{gathered}
$$

Substituting $\gamma=c k /(\sigma-1)+f^{d}$ and $\phi \equiv \tau^{-k}\left(\frac{c+f^{d}}{f^{x}-f^{d}}\right)^{\frac{k-\sigma+1}{\sigma-1}} \frac{\left(c+f^{d}\right)}{\gamma}$ delivers (9).

Since $\frac{\gamma(\sigma-1)}{k-\sigma+1}>0$ the cutoffs are strictly positive as long as $\phi<1$ and $\frac{1}{\phi}>\left(\frac{w_{j}}{w_{i}}\right)^{\frac{\sigma k}{\sigma-1}}$. Under the parameter restrictions $k>\sigma-1$ and $c<f^{x}-2 f^{d}$ it can easily be shown that $\phi<1$ holds true. Moreover, assuming that only domestically active firms operate on the export market requires $\frac{1}{\phi}>\left(\frac{w_{i}}{w_{j}}\right)^{\frac{\sigma k}{\sigma-1}}$ as will be proven in Appendix C below. For symmetric countries, i.e. $w_{i}=w_{j}$, it can easily be shown that the cutoffs are strictly increasing in $c$ if $\frac{\partial \phi}{\partial c}>0$ which holds true for $k>\sigma-1$. For asymmetric countries the effect of $c$ on the cutoffs cannot be determined without taking into account the impact of $c$ on the relative wages $w_{j} / w_{i}$. This, however, cannot be done analytically, but requires to solve the model numerically.

\section{Ensuring that only domestically active firms start exporting}

It is a common assumption of the heterogenous-firms literature and in line with empirical evidence, that exporting firms also serve the domestic market. This is equivalent to requiring $\varphi_{i j}^{*}>\varphi_{i i}^{*}$ and $\varphi_{j i}^{*}>\varphi_{j j}^{*}$ which at the same time ensures that the conditional export probability ranges between zero and unity. In our framework, these assumptions are reflected by the following constraints in the symmetric and asymmetric case:

1. For symmetric countries, $w_{i}=w_{j}$ and $\varphi_{i i}^{*}=\varphi_{j j}^{*}$, and the export cutoffs of the two countries can be stated as functions of the domestic cutoffs (see Section 3):

$$
\varphi_{i j}^{*}=\tau\left(\frac{f^{x}-f^{d}}{f^{d}+c}\right)^{\frac{1}{\sigma-1}} \varphi_{j j}^{*} \quad \varphi_{j i}^{*}=\tau\left(\frac{f^{x}-f^{d}}{f^{d}+c}\right)^{\frac{1}{\sigma-1}} \varphi_{i i}^{*} .
$$


Accordingly, for symmetric countries and trade costs converging to unity the export cutoffs are greater than their domestic counterparts as long as $f^{x}-f^{d}>f^{d}+c$ is satisfied. Since $c \geq 0$ this requires that the additional costs for becoming an exporter firm exceed the fixed costs for setting up a domestic firm $f^{x}-f^{d}>f^{d}$.

2. For asymmetric countries, ensuring that only domestically active firm export restricts the support region of $w_{i}$ and $w_{j}$ to

$$
\begin{gathered}
\frac{w_{i}}{w_{j}}<\left(\frac{f^{x}-f^{d}}{\phi \gamma}\right)^{\frac{\sigma-1}{\sigma k}} \wedge \frac{w_{j}}{w_{i}}<\left(\frac{f^{x}-f^{d}}{\phi \gamma}\right)^{\frac{\sigma-1}{\sigma k}} \\
\text { or } \\
\frac{w_{i}}{w_{j}}<\left(\frac{1}{\phi}\right)^{\frac{\sigma-1}{\sigma k}} \wedge \frac{w_{j}}{w_{i}}<\left(\frac{1}{\phi}\right)^{\frac{\sigma-1}{\sigma k}}
\end{gathered}
$$

where $\gamma \equiv c k /(\sigma-1)+f^{d}$ and $\phi \equiv \tau^{-k}\left(\frac{c+f^{d}}{f^{x}-f^{d}}\right)^{\frac{k-\sigma+1}{\sigma-1}} \frac{\left(c+f^{d}\right)}{\gamma}$. Note that $f^{x}-f^{d} \lesseqgtr \gamma$ depending on whether $c k /(\sigma-1) \lesseqgtr f^{x}-2 f^{d}$. In our general setting, we allow for parameter constellations that render either the first constraint (in case $\left.c k /(\sigma-1)>f^{x}-2 f^{d}\right)$ or the second constraint binding (in case $\left.c k /(\sigma-1)<f^{x}-2 f^{d}\right)$. In both situations the applicable constraint constitutes a necessary and sufficient condition for $\varphi_{i j}^{*}>\varphi_{i i}^{*}$ and $\varphi_{j j}^{*}>\varphi_{j i}^{*}$ as will be shown in the following.

Think of a situation where $w_{i}>w_{j}>0$, and $\frac{w_{i}}{w_{j}}>\left(\frac{1}{\phi}\right)^{\frac{\sigma-1}{\sigma k}}$. This implies that the domestic cutoff in $j\left(\varphi_{j j}^{*}\right)$ as derived in Appendix B is negative while the domestic cutoff in $i\left(\varphi_{i i}^{*}\right)$ is positive. Recall that $f^{x}-f^{d}>0$, such that $\varphi_{i i}^{*}>0$ and $\varphi_{j j}^{*}<0$ imply from equation (7) that the export cutoff in $j\left(\varphi_{j i}^{*}\right)$ is positive and the export cutoff in $i$ $\left(\varphi_{i j}^{*}\right)$ is negative. Hence, under the assumptions that $w_{i}>w_{j}>0$ and $\frac{w_{i}}{w_{j}}>\left(\frac{1}{\phi}\right)^{\frac{\sigma-1}{\sigma k}}$ the ordering of domestic and export cutoffs in region $i$ is $\varphi_{i j}^{*}<\varphi_{i i}^{*}$ which means that there are some firms in $i$ that export, but do not produce for the domestic market. Similarly, assuming $w_{j}>w_{i}>0$ and $\frac{w_{j}}{w_{i}}>\left(\frac{1}{\phi}\right)^{\frac{\sigma-1}{\sigma k}}$ yields $\varphi_{j i}^{*}<\varphi_{j j}^{*}$ such that some firms in $j$ produce for the export market only. Accordingly, a necessary assumption for precluding firms in both regions from exporting without producing for the domestic market is $\frac{w_{i}}{w_{j}}<$ $\left(\frac{1}{\phi}\right)^{\frac{\sigma-1}{\sigma k}} \wedge \frac{w_{j}}{w_{i}}<\left(\frac{1}{\phi}\right)^{\frac{\sigma-1}{\sigma k}}$ which ensures that $\varphi_{i j}^{*}$ and $\varphi_{j i}^{*}$ are positive. However, if $f^{x}-f^{d}<\gamma$ this condition may not be sufficient as there could be solutions where all cutoff productivities are positive but $\varphi_{i j}^{*}<\varphi_{i i}^{*}$ or $\varphi_{j i}^{*}<\varphi_{j j}^{*}$ still applies. From equations 
(7) we observe that $\frac{w_{i}}{w_{j}}<\left(\frac{f^{x}-f^{d}}{\phi \gamma}\right)^{\frac{\sigma-1}{\sigma k}} \wedge \frac{w_{j}}{w_{i}}<\left(\frac{f^{x}-f^{d}}{\phi \gamma}\right)^{\frac{\sigma-1}{\sigma k}}$ has to be fulfilled in such a scenario in order to guarantee $\varphi_{i j}^{*}>\varphi_{i i}^{*}$ and $\varphi_{j i}^{*}>\varphi_{j j}^{*}$.

Together, the two constraints on relative wages from above constitute sufficient conditions for ensuring that only domestic producers become exporters. Again, consider a situation where $w_{i}>w_{j}$, but let the relative wage constraints in (C.1) be satisfied for now. Then from the domestic-cutoff equation (9), both $\varphi_{i i}^{*}$ and $\varphi_{j j}^{*}$ are strictly positive. Taking a closer look at equation (9) reveals that - under the above assumptions $\left(\frac{1}{\phi}\right)^{\frac{\sigma-1}{\sigma k}}>\frac{w_{i}}{w_{j}}$, and $\left(\frac{1}{\phi}\right)^{\frac{\sigma-1}{\sigma k}}>\frac{w_{j}}{w_{i}}-$ the country with the higher wage rate features the lower domestic cutoff productivity. That is $\varphi_{j j}^{*}>\varphi_{i i}^{*}$ for $w_{i}>w_{j}$ which under the constraints $\frac{w_{i}}{w_{j}}<\left(\frac{f^{x}-f^{d}}{\phi \gamma}\right)^{\frac{\sigma-1}{\sigma k}} \wedge \frac{w_{j}}{w_{i}}<\left(\frac{f^{x}-f^{d}}{\phi \gamma}\right)^{\frac{\sigma-1}{\sigma k}}$ implies from equation (7) that $\varphi_{i j}^{*}>\varphi_{j i}^{*}$, $\varphi_{i j}^{*}>\varphi_{i i}^{*}$, and $\varphi_{j i}^{*}>\varphi_{j j}^{*}$ hold true. Therefore, the overall productivity ordering for the $w_{i}>w_{j}$ scenario is $\varphi_{i j}^{*}>\varphi_{j i}^{*}>\varphi_{j j}^{*}>\varphi_{i i}^{*}>0$. Similarly, the $w_{j}>w_{i}$ scenario yields $\varphi_{j i}^{*}>\varphi_{i j}^{*}>\varphi_{i i}^{*}>\varphi_{j j}^{*}>0$ under the relative wage constraints.

\section{Deriving the symmetric equilibrium, the agglomeration equilibrium, and the break point}

At $\lambda=1 / 2$ it holds true that $d W_{i}=-d W_{j}$. Therefore, it follows that the symmetric equilibrium is stable as long as an additional worker in $i$ decreases real wages in $i$ - which corresponds to an increase of real wages in $j$ and a negative real wage differential $W_{i}-W_{j}$. Hence, the break point is characterized by the level of trade costs that satisfies:

$$
\left.\frac{d W_{i}}{d \lambda}\right|_{\lambda=1 / 2}=0 \quad \Leftrightarrow \quad d w_{i}=\alpha w_{i} \frac{d P_{i}}{P_{i}} \text { for } \lambda=1 / 2
$$

Solving for the break point involves tedious algebra. First, we totally differentiate the labor market clearing condition $(L M C)$ and the goods-market-clearing condition $(G M C)$. Second, we use this equation system to compute the total derivatives of the price index, the total derivative of the wage rate, and the total derivative of the number of firms (which is part of the price index). Second, we determine the equilibrium values of $w_{i}, P_{i}$, and $M_{i}$ at $\lambda=1 / 2$ and evaluate the above mentioned total derivatives at the symmetric equilibrium. 


\section{Symmetric equilibrium:}

At the symmetric equilibrium, it can easily be shown from the goods-market-clearing condition $(G M C)$ that the wage is given by $w_{i}=\frac{\alpha L_{i}}{(1-\alpha) H_{i}}$. To simplify computation we follow most of the literature and normalize the total number of low-skilled workers to $L=L_{i}+L_{j}=1-\alpha$ and the total number of high-skilled workers to $H_{i}+H_{j}=\alpha$. This implies that the high-skilled wage under symmetry is unity. With $\lambda=1 / 2, w_{i}=w_{j}=1$, and $M_{i}=M_{j}$, the price index from (10) can be simplified to:

$$
\begin{aligned}
P_{i} & =M_{i i}^{\frac{1}{1-\sigma}}\left[\left(\frac{\sigma w_{i}}{(\sigma-1) \widetilde{\varphi}_{i i}}\right)^{1-\sigma}+\left(\varphi_{j j}^{*} / \varphi_{j i}^{*}\right)^{k}\left(\frac{\tau \sigma w_{j}}{(\sigma-1) \widetilde{\varphi}_{j i}}\right)^{1-\sigma}\right]^{\frac{1}{1-\sigma}} \\
& =M_{i i}^{\frac{1}{1-\sigma}} \frac{\sigma}{(\sigma-1)}\left(\frac{k}{k-\sigma+1}\right)^{\frac{1}{1-\sigma}}\left(\frac{k-\sigma+1}{\gamma(\sigma-1)(1+\phi)}\right)^{\frac{1}{k}}\left[1+\phi\left(f^{d}+c\right) \gamma\right],
\end{aligned}
$$

where $\gamma=\frac{c k}{\sigma-1}+f^{d}$ and $\phi=\tau^{-k}\left(\frac{c+f^{d}}{f^{x}-f^{d}}\right)^{\frac{k-\sigma+1}{\sigma-1}} \frac{\left(c+f^{d}\right)}{\gamma}$. Using the price index jointly with the labor-market constraint $(L M C)$ we can compute the equilibrium number of firms under symmetry:

$$
M_{i i}=\frac{\alpha(1+k-\sigma) \psi}{2 \sigma\left[f^{d}(1+k-\sigma)+\gamma(k \phi+\sigma-1)\right]} .
$$

\section{Break point:}

Using the total derivatives of the labor market constraint $(L M C)$ together with the total differential of the goods-market-clearing condition $(G M C)$ - both evaluated at $\lambda=1 / 2-$ we can compute $\frac{d w_{i}}{d \lambda}$ and $\frac{d M_{i i}}{d \lambda}$. Finally, we need to compute the total derivative of the price index and evaluate it at $\lambda=1 / 2$ as well. Plugging in $\frac{d w_{i}}{d \lambda}, \frac{d M_{i i}}{d \lambda}$, and $d P\left(\frac{d w_{i}}{d \lambda}, \frac{d M_{i i}}{d \lambda}\right)$ into the definition of the break point from (D.2) we get the following condition that describes the critical parameter constellation for the symmetric equilibrium to just become unstable:

$$
\begin{aligned}
& \frac{(\sigma-1)^{2}(\phi-1)}{\alpha \sigma(\phi+1)}\left[\gamma \phi-A\left(c+f^{d}\right)\right]= \\
& \left(c+f^{d}\right)(\sigma-1) A+\gamma \phi(1+2 k-\sigma)-\frac{2 k^{2} \gamma \phi\left[\left(c+f^{d}\right) A+\gamma \phi\right]}{f^{d}(k-\sigma+1)+\gamma(k \phi+\sigma-1)},
\end{aligned}
$$

where $A=\frac{1-\alpha}{1+\alpha}$. This condition yields the break point $\tau_{B}$ and it is plotted for different parameter constellations in Figure 3 


\section{Agglomeration equilibrium:}

At the agglomeration equilibrium it holds that $\lambda=1$ and hence, $H_{j}=M_{j}=0$. With the above normalization the labor market clearing condition becomes:

$$
\begin{aligned}
H_{i}= & M_{i}\left[\frac{\alpha\left(L_{i}+w_{i} H_{i}\right)}{P_{i}^{1-\sigma}}\left(\frac{\sigma w_{i}}{\sigma-1}\right)^{-\sigma}\left(\widetilde{\varphi}_{i}\right)^{\sigma-1}+f^{d} / \psi\right] \\
& +M_{i}\left(\varphi_{i}^{*} / \varphi_{i j}^{*}\right)^{k}\left[\tau^{1-\sigma} \frac{\alpha L_{j}}{P_{j}^{1-\sigma}}\left(\frac{\sigma w_{i}}{\sigma-1}\right)^{-\sigma}\left(\widetilde{\varphi}_{i x}\right)^{\sigma-1}+f^{x} / \psi\right]+M_{i}\left(\varphi_{i}^{*}\right)^{k} / \psi .
\end{aligned}
$$

The price indices with full agglomeration simplify to :

$$
P_{i}=M_{i}^{\frac{1}{1-\sigma}}\left(\frac{\sigma w_{i}}{(\sigma-1) \widetilde{\varphi}_{i}}\right), P_{j}=\left(\varphi_{i}^{*} / \varphi_{i j}^{*}\right)^{\frac{k+1-\sigma}{1-\sigma}} P_{i} \tau
$$

The goods-market-clearing conditions imply that the high-skilled wage is unity in the agglomeration equilibrium:

$$
\begin{aligned}
M_{i}\left(\varphi_{i}^{*} / \varphi_{i j}^{*}\right)^{k} \frac{\alpha E_{j}}{P_{j}^{1-\sigma}} p_{i x}\left(\widetilde{\varphi}_{i j}\right)^{1-\sigma} & =(1-\alpha) w_{i} H_{i}-\alpha L \\
w_{i} & =1
\end{aligned}
$$

The marginal firms that enter the domestic and exporting markets are characterized by the following conditions:

$$
r_{i}\left(\varphi_{i}^{*}\right)=\sigma f^{d} w_{i}(1+\rho)+\sigma \frac{B w_{i}}{\Delta \psi}, r_{i j}\left(\varphi_{i j}^{*}\right)=\sigma\left(f^{x}-f^{d}\right) w_{i}(1+\rho) .
$$

Employing the above conditions jointly with the price indices we obtain the conditional export probability:

$$
\left(\frac{\varphi_{i}^{*}}{\varphi_{i j}^{*}}\right)^{k}=\left(\frac{1-\alpha}{1+\alpha}\right) \frac{f^{d}(1+\rho)+\frac{B}{\Delta \psi}}{\left(f^{x}-f^{d}\right)(1+\rho)}
$$

From the free-entry condition (FE) we derive the cutoff productivity in the agglomeration equilibrium: Combining the with free entry from manuscript equation (FE) we obtain the cutoff productivity:

$$
\varphi_{i i}^{*}=\frac{\sigma-1}{k-\sigma+1}\left[\frac{k c}{\sigma-1}+f^{d}+\frac{1-\alpha}{1+\alpha}\left(f^{d}+c\right)\right] .
$$




\section{References}

Acemoglu, D. and F. Zilibotti (1997), Was Prometheus Unbound by Chance? Risk, Diversification, and growth, Journal of Political Economy 105, 709-51.

Antràs, P. and R.J. Caballero (2009), Trade and capital flows: A financial frictions perspective, Journal of Political Economy 117, 701-744.

Antràs, P., M.A. Desai and C.F. Foley (2009), Multinational firms, FDI flows, and imperfect capital markets, Quarterly Journal of Economics 124, 1171-1219.

Baldwin, R.E., R. Forslid, P. Martin, G.I.P. Ottaviano, and F. Robert-Nicoud (2003), Economic geography and public policy. Princeton University Press, Princeton, NJ.

Beck, T. (2002), Financial development and international trade. Is there a link?, Journal of International Economics 57, 107-131.

Beck, T. (2003), Financial dependence and international trade, Review of International Economics 11, 296-316.

Beck, T., A. Demirgüç-Kunt, L. Laeven, and R. Levine (2008), Finance, firm size, and growth, Journal of Money, Credit, and Banking 40, 1379-1405.

Beck, T., A. Demirgüç-Kunt, and V. Maksimovic (2005), Financial and legal constraints to growth: Does firm size matter?, Journal of Finance 60, 137-177.

Beck, T., A. Demirgüç-Kunt, and R. Levine (2007), Finance, inequality and the poor, Journal of Economic Growth, 12, 27-49.

Chor, D., F. Foley and K. Manova (2008), Host country financial development and MNC activity, Stanford University, mimeo.

Clarke, G.R.G., L.C. Xu, and H. Zou (2006), Finance and income inequality: what do the data tell us?, Southern Economic Journal, 72, 578-596.

Davis, D. and D. Weinstein (2002), Bones, bombs, and break points: the geography of economic activity, American Economic Review 92, 1269-1289.

Davis, D. and D. Weinstein (2003), Market access, economic geography and comparative advantage: an empirical assessment, Journal of International Economics 59, 1-23. 
Egger, H. and U. Kreickemeier (2008), Firm heterogeneity and the labor market effects of trade liberalization, International Economic Review 50, 187-216.

Egger, H. and U. Kreickemeier (2012), Fairness, trade, and inequality, Journal of International Economics 86, 87-96.

Egger, P. and C. Keuschnigg (2010a), Innovation, trade and finance, Working Paper.

Egger, P. and C. Keuschnigg (2010b), Corporate finance and comparative advantage, Working Paper.

Ehrlich, M. v. and T. Seidel (2013a), Regional implications of financial market development: Credit rationing, trade, and location, CESifo Working Paper No. 4063.

Ehrlich, M. v. and T. Seidel (2013b), More similar firms - more similar regions? On the role of firm heterogeneity for agglomeration, Regional Science and Urban Economics 43, 539-548.

Ellison, G., E.L. Glaeser, and W.R. Kerr (2010), What causes industry agglomeration? Evidence from coagglomeration patterns, American Economic Review 100, 1195-1213.

EU Commission (2011), Panorama inforegio 40 - cohesion policy 2014-2020 investing in Europe's regions, available at http://ec.europa.eu/regional_policy/sources/ docgener/panorama/pdf/mag40/mag40_en.pdf.

Felbermayr, G., J. Prat and H.-J. Schmerer (2011), Globalization and labor market outcomes: Wage bargaining, search frictions, and firm heterogeneity, Journal of Economic Theory 146, 39-73.

Hakenes, H. and J. Kranich (2010), Capital market frictions and economic geography, unpublished manuscript, University of Hannover.

Hanson, G.H. and C. Xiang (2004), The home-market effect and bilateral trade patterns, American Economic Review 94, 1108-1129.

Helpman, E. and O. Itskhoki (2010), Labor market rigidities, trade and unemployment, Review of Economic Studies 77, 1100-1137. 
Helpman, E., O. Itskhoki, and S. Redding (2010), Inequality and unemployment in a global economy, Econometrica 78, 1239-1283.

Holmstrom, B. and J. Tirole (1997), Financial intermediation, loanable funds, and the real sector, Quarterly Journal of Economics 112, 663-691.

Krugman, P. (1981), Trade, accumulation, and uneven development, Journal of Development Economics 8, 149-161.

Krugman, P. (1991), Increasing returns and economic geography, Journal of Political Economy 99, 483-499.

Krugman, P. and A. Venables (1995), Globalization and the inequality of nations, Quarterly Journal of Economics 110, 857-880.

La Porta, R., Lopez-de-Silanes, F., Shleifer, A. and R.W. Vishny, (1997), Legal determinants of external finance, Journal of Finance, 52, 1131-1150.

Lewis, W.A. (1977), The evolution of international economic order, Princeton: Princeton University Press.

Liang, Z. (2006), Financial development and income distribution: A system panel analysis with application to urban China, Journal of Economic Development, 31, 1-21.

Lucas, R.E. (1978), On the size distribution of business firms, Bell Journal of Economics 9, 508-523.

Manova, K. (2008), Credit constraints, equity market liberalizations and international trade, Journal of International Economics 76, 33-47.

Manova, K. (2012), Credit constraints, heterogeneous firms and international trade, Review of Economic Studies, forthcoming.

Martin, P. and H. Rey (2004), Financial super-markets: Size matters for asset trade, Journal of International Economics 64, 335-361.

Martin, P. and C.A. Rogers (1995), Industrial location and public infrastructure, Journal of International Economics 39, 335-351.

Matsuyama, K. (2004), Financial market globalization, symmetry-breaking and endogenous inequality of nations, Econometrica 72, 853-884. 
Melitz, M.J. (2003), The impact of trade on intra-industry reallocations and aggregate industry productivity, Econometrica 71, 1695-1725.

Muûls, M. (2008), Exporters and credit constraints. A firm-level approach, National Bank of Belgium Working Paper No. 139.

Myrdal, G. (1957), Economic theory and underdeveloped regions, London: Duckworth.

Pflüger, M. (2004), A simple, analytically solvable, chamberlinian agglomeration model, Regional Science and Urban Economics 34, 565-573.

Redding, S.J. and D.M. Sturm (2008), The costs of remoteness: Evidence from German division and reunification, American Economic Review 98, 1766-1797.

Tirole, J. (2006), The theory of corporate finance. Princeton: Princeton University Press. 


\section{Center for Regional Economic Development (CRED)}

University of Bern

Schanzeneckstrasse 1

P.O.Box 8573

CH-3001 Bern

Telephone: +41316313711

Fax: +41316313415

E-Mail: info@cred.unibe.ch

Website: http://www.cred.unibe.ch

The Center for Regional Economic Development (CRED) is an interdisciplinary hub for the scientific analysis of questions of regional economic development. The Center encompasses an association of scientists dedicated to examining regional development from an economic, geographic and business perspective.

\section{Contact of the authors:}

Maximilian von Ehrlich

University of Bern

Department of Economics

Schanzeneckstrasse 1, P.O.Box 8573

CH-3001 Bern

Telephone: +41316318075

Email: maximilian.vonehrlich@vwi.unibe.ch

Tobias Seidel

University of Duisburg-Essen

Lotharstraße 65

D-47057 Duisburg

Telephone: +49 (203) 379 - 2625

Email: tobias.seidel@uni-due.de

This paper can be downloaded at:

http://www.cred.unibe.ch/content/forschung/cred research_papers/index ger.html 